\title{
Tradisi Intelektual Fardhu Ain dan Fardhu Kifayah Pesantren dalam Menanggulangi Terorisme
}

\author{
Muhammad Taqiyuddin \\ Universitas Darussalam Gontor \\ Email: taqiyuddin@unida.gontor.ac.id \\ Received: March 8, 2021 | Accepted: June 19, 2021
}

\begin{abstract}
Most people believe that religion and ideology contribute to the spread of terrorism. Thus, it can be seen from the method of text interpretation and the implementation of over-textual and rigid interpretations in religious studies that are very instant and indoctrinal; which resulted in the spread of 'radicalism'. This aspect forgets the essence of Islamic education which emphasizes tolerance, courtesy, and love for peace. Conversely, Islamic studies that are too contextual, will eliminate the epistemological footing; that is, their identity and essence, because they merely follow all the social changes that continue to occur without regard to the wisdom and wisdom of local wisdom. Thus, the search for knowledge is no longer sacred and then encourages the loss of etiquette (loss of adab). Therefore, conceptual efforts in Islamic education need to be carried out appropriately. This qualitative model study seeks to collect fragments and data from various studies based on Islamic turots on the fardhu 'ain and fardhu kifayah models and their relevance in various contexts of Islamic studies such as integrative aspects between religious science and social science and contemporary technology. Through content analysis, thematic analysis as well as critical discourse analysis. This study concludes that the scientific equilibrium based on fardhu 'ain and fardhu kifayah has proven to make Islamic insights and discourse broad and flexible, so as to give birth to attitudes that both physically and spiritually represent the essence of Islamic teachings themselves.
\end{abstract}

\begin{abstract}
Abstrak
Sebagian besar orang percaya bahwa agama dan ideologi turut 'menyumbang' penyebaran terorisme. Demikian, terlihat dari metode interpretasi teks dan implementasi tafsiran yang over-tekstual dan rigid dalam kajian keagamaan yang sangat instan dan indoktriner; yang mengakibatkan tersebarnya 'radikalisme'. Aspek tersebut melupakan esensi pendidikan Islam yang menekankan sikap toleran, santun, dan cinta damai. Sebaliknya, kajian keislaman yang terlalu kontekstual, akan


menghilangkan pijakan epistemologis; yakni identitas dan esensinya, karena hanya semata mengikuti segala perubahan sosial yang terus terjadi tanpa memperhatikan nilai luhur yang hikmatis serta kearifan lokal. Sehingga, pencarian ilmu tidak lagi menjadi sakral lantas mendorong hilangnya adab (loss of adab). Oleh karena itulah, upaya konseptual dalam pendidikan Islam perlu dilakukan secara tepat. Kajian model kualitatif ini berusaha mengumpulkan fragmen dan data dari berbagai penelitian yang berdasarkan turots Islam tentang model fardhu 'ain dan fardhu kifayah serta relevansinya dalam berbagai konteks studi Islam seperti aspek integratif antara ilmu agama dengan ilmu sosial serta teknologi kontemporer. Melalui analisa konten (content analysis), tematis (thematic analysis) serta analisa diskursus (critical discourse analysis). Kajian ini menyimpulkan bahwa kesetimbangan keilmuan yang didasari akan fardhu 'ain dan fardhu kifayah terbukti menjadikan wawasan keislaman dan wacananya menjadi luas dan fleksibel, sehingga mampu melahirkan sikap yang secara lahir dan batin merepresentasikan esensi dari ajaran Islam itu sendiri.

\section{Keywords}

Fardhu 'ain, fardhu kifāyah, pesantren (Islamic boarding school), terorism

\section{Pendahuluan}

Seringkali, penanggulangan terorisme hanya dilihat dari aspek 'urgensi liberalisasi Pemikiran Islam' atau menjadikan orang muslim berfikir moderat; agar tidak menjadi konservatif atau radikal. Meski, kadangkala makna moderat menjadi perebutan antara Islam dan Barat itu sendiri. Perspektif ini berlatar belakang peristiwa 9/11 yang terjadi di Amerika. Yang mana, otoritas pemerintah di sana menyebut bahwa pembajakan pesawat yang ditabrakkan ke gedung World Trade Center tersebut, didalangi oleh jaringan teroris internasional yang diidentifikasi sebagai kelompok jihadis Afghanistan; al-Qaeda. Tokoh yang memimpinnya adalah Osama bin Laden. (Shaw, 2012) Pada masa selanjutnya, berbagai lembaga think tank di sana memberi saran untuk 'membendung' dan mencegah arus terorisme di masa depan, dengan cara 'mengubah' apa yang menjadi pikiran dan wacana umat Islam secara keseluruhan; agar mau menerima supremasi Amerika beserta budaya dan paket-paket kebijakannya. (Zarkasyi, 2012)

Bentuk yang nyata, salah satunya tercermin dalam bidang pendidikan. Wacana unik seperti kebebasan, feminisme, juga fiqh dan ushul fiqh model baru hingga wacana yang menegasikan jihad dalam Islam turut disosialisasikan dalam kurikulumnya. (Munjahid, 2011) Dalam wacana teologi, ide pluralisme yang sebagian didasari oleh ide John Hick, Rene 
Guenon, hingga Schuon dikampanyekan sebagai upaya menyadarkan bahwa semua agama adalah benar. Sehingga, tidak perlu lagi untuk merasa paling benar dan menyalahkan pihak lain; yang berujung perdebatan keras dan radikalisme serta diskriminasi dan persekusi. Yang mana, radikalisme tersebut mendorong kemunculan terorisme. (Abu-Munshar, 2010)

Tawaran lain, yakni berkaitan dengan pendidikan sains. Tujuannya, agar terorisme dapat ditanggulangi penyebarannya. Khususnya, penyebaran ide-ide terorisme melalui platform media sosial seperti Telegram, WhatsApp, Facebook, dan lainnya. (Lu and Yu, 2018) Sehingga, ada ide untuk mengawasi transaksi informasi dan elektronik yang beredar melalui platform tersebut. Pendidikan sains dan teknologi dianggap urgen; karena para teroris diasumsikan telah terkoordinir secara internasional dan rapi. Serta menguasai teknologi yang belum dapat dibayangkan; sebagaimana yang dicitrakan oleh Amerika dan lainnya. (Chatfield, Reddick and Brajawidagda, 2015)

Namun berbagai tawaran di atas menuai pro dan kontra; yang mana pihak tradisional lebih cenderung kontra. Hal ini, karena wacana di atas adalah asing; yakni tidak ada dalam tradisi kitab kuning yang merupakan warisan intelektual ulama nusantara yang juga diwariskan dari generasi sebelumnya secara bersanad. (Bizawie, 2015) Transmisinya, melalui tradisi sorogan, bandongan, atau semacam talaqqī lainnya. Karenanya, tanpa menegasikan semangat para 'modernis' yang membawa ide-ide kontemporer di atas; sejatinya, tradisi keilmuan Islam di Indonesia justru lebih urgen untuk digali secara historis. (Zarkasyi, 2015a) Dikarenakan, berbagai tradisi intelektual dan permasalahan umat juga dihadapi oleh ulama pada masa lalu. Sehingga, peran bahkan prediksi para ulama tersebut masih relevan; karena visionernya pandangan para ulama tersebut. Salah satu kitab yang mengandung aspek pendidikan; yang secara umum dikenali oleh komunitas muslim Indonesia, adalah Ihyā Ulümuddin karya Imām alGhazālī. Selain itu, masih banyak pula kitab lainnya, seperti Ta'tìm Muta'allim karya al-Zarnujī.

Dalam tingkat pendidikan tinggi, kurikulum dan metodologi yang integratif telah terbukti secara teoritis dapat dipertanggungjawabkan secara ilmiah. Secara praktis, ide pedagogis berupa pendidikan sains dan agama - yang mana sains merupakan lambang modernitas dan agama merupakan lambang tradisi yang hikmatis dan sakral berdimensi ilähiyahdapat disatukan dengan paradigma tertentu. Sikap ini setidaknya moderat, yakni menengahi antara teks dengan konteks; juga antara liberal dengan ekstrim. (Abdullah, 2017) Hal ini, sejatinya dapat kita temukan relevansi dalam pemikiran Imam Ghazālī, al-Zarnūjī dan beberapa tokoh yang terpengaruh oleh karya-karyanya. Yang secara khusus, kajian pemikiran mengenai fardhu 'ain dan fardhu kifäyah yang sedemikian banyak ditemukan 
di lingkungan pesantren. Kajian inilah yang akan didalami dalam tulisan singkat ini.

Pendidikan merupakan sebuah proses yang sangat penting. Hal ini telah disadari oleh berbagai negara dan bangsa manapun. Secara faktual, pendidikan dalam Islam merupakan komponen penting dari peradaban Islam itu sendiri. Yang mana, tujuannya adalah menjadikan individu menjadi orang yang baik; secara rohani maupun jasmani. Secara praktis, tentu dimulai dari perbaikan akhlak; sebagaimana dilakukan oleh nabi pasca perbaikan aqidah bagi orang muslim pada era dakwah di Makkah. Hamid Fahmy memberikan analisa, bahwa periode Makkah adalah fase di mana turunnya wahyu banyak berkenaan tentang hal-hal konseptual yang fundamental, seperti Tuhan, Hari Berbangkit, Taqdir baik dan buruk, dan hal-hal lain yang dikategorikan sebagai worldview Islam. (Hussin, Noh and Tamuri, 2014; Fahmy Zarkasyi, 2015) Hal ini menandakan, bahwa penguasaan akan dasar-dasar keilmuan Islam menjadi penting sebagai elemen kurikulum pembelajaran Studi Islam; khususnya yang mencakup worldview Islam, baik Aqidah maupun Syariah.

Selaras dengan itu, secara khusus Claire Alkouatli menyebut bahwa sasaran dakwah Nabi adalah orang dewasa ( $b \bar{a} l i g h)$ yang mana juga berakal (āqil). Sehingga, metode dakwah nabi merupakan bagian yang identik dengan aspek pedagogis maupun andragogis; yang turut menjadi faktor perkembangan Islam pada masa itu. Apalagi dipandang dari sudut pandang keberadaan beliau yang selalu mendampingi umat Islam yang minoritas pada masa itu. Kemampuan dan kapasitas nabi sebagai Edukator, tidak terlepas dari peran petunjuk wahyu; yang mana di dalamnya terdapat pengetahuan yang benar lagi berdimensi hikmah. (Alkouatli, 2018) Aktivitas dakwah nabi, dapat digolongkan sebagai proses transformasi pengetahuan untuk mendatangkan kesadaran untuk ber-Islam, yakni melalui hidāyah yang dipicu oleh dakwah. Sikap nabi tentu sangat toleran lagi santun, tanpa menafikan ketegasannya dalam menggenggam prinsip agar tidak akan sekali-kali meninggalkan dakwah Islam dengan taruhan nyawa sekalipun.

Pada perkembangannya, proses dakwah sebagai transfer pengetahuan selalu mengalami tantangan yang cukup signifikan. Amin Abdullah turut menyebut, bahwa tantangan kontemporer dalam pendidikan tinggi untuk mayoritas Islam saat ini adalah 'tantangan ilmu' (pursuit of knowledge). Bentuknya, para siswa juga mahasiswa hanya menguasai ilmu pengetahuan dan teknologi serta agama secara parsial; berujung pada penafsiran teks keagamaan yang terlalu tekstual dan rigid. Seolah, alternatif untuk beragama hanya didominasi oleh suatu kultur saja. Hal ini menjadi penting untuk dipetakan, bahwa Studi Islam dapat digolongkan sebagai Islamic Studies (Dirāsāt al-Islāmiyyah), Religious Knowledge (Ulūm al-Dìn), dan Islamic Thought (al-Fikr al-Islāmī). Dan 
kesemuanya memiliki obyek kajian masing-masing sesuai proporsinya. Ketidakmampuan dalam membedakan subyek dan obyek kajian, akan membawa kepada interpretasi Islam secara tidak tepat. Sebagaimana munculnya beberapa golongan muslim yang disebut radikal sebagaimana di atas. Yakni, tidak melihat aspek integratif antara keilmuan di Barat dengan Islam serta peradaban lainnya. (Abdullah, 2014, 2017; Siswanto, 2015)

Hal ini tentu mendorong untuk perlunya usaha perumusan konseptual mengenai pendidikan Islam, yang mana basisnya adalah pemikiran keagamaan. Sumbernya pun, perlu diperkaya dengan kajian turats dan komparasi teori kontemporer yang telah melalui proses screening atas aspek Islami yang dapat diambil atau diadaptasikan ke dalam teori pendidikan Islam secara tepat.

\section{Metode}

Penelitian model pustaka ini menggunakan metode pengumpulan data secara kualitatif atas beberapa literatur beserta komentar atasnya (Matua and Van Der Wal, 2015; Moser and Korstjens, 2018) tentang pendidikan fardhu 'ain dan fardhu kifayah yang digali dari khazanah intelektual Islam klasik, serta menggunakan analisa konten dan tematik dalam menghubungkannya dengan diskursus dunia pendidikan kontemporer yang digadang-gadang sebagai upaya Islam untuk menangkal terorisme. Asumsi dasarnya, pendidikan fardhu 'ain dan fardhu kifayah merupakan skema pendidikan berdasarkan urgensi ilmu tersebut. Juga orientasi kehidupan seorang muslim yang berdimensi dunia dan akhirat. Sehingga, untuk menjadi seorang muslim membutuhkan ilmu fardhu 'ain yang wajib dimengerti dalam skala menjalankan kewajiban; meski ada pula yang mempelajari ilmu tentang yang wajib dalam tingkat yang lebih tinggi. Ini tentu menjadi fardhu kifayah yang cukup dilakukan oleh otoritas keagamaan, yakni ulama yang kompeten. Hal ini telah secara luas diterapkan di berbagai pesantren dengan tradisi keilmuannya. (Solichin, 2018). Pendekatan penelitian pustaka ini, dilakukan melalui analisa atas berbagai penelitian yang mengungkap tradisi ilmiah fardhu 'ain dan fardhu kifayah khususnya pesantren. Sedikit banyak, penelitian ini akan fokus kepada fakta-fakta mengenai perkembangan pesantren serta coraknya; juga hasil studi yang dilakukan ilmuan yang mengalami kehidupan di pesantren maupun oleh outsider. Secara konseptual, penelitian ini mengeksplorasi literatur tentang fardhu 'ain dan fardhu kifayah yang awalnya dicetuskan termanya oleh Imam Ghazali (Sa'ari, 1999; Kholili, 2014), lalu dijabarkan kembali oleh penerusnya, yakni al-Zarnuji (Huda et al., 2016). Jika melihat pembahasannya, terdapat beberapa hal yang esensial, yakni tentang bagaimana memperoleh ilmu serta mengamalkannya. Secara teknis, metodologi mempelajari ilmu agama secara integratif dengan klasifikasi 
fardhu 'ain dan fardhu kifayah dikaji lebih kritis. Khususnya hal-hal yang dapat menjadi poin untuk mencegah radikalisme dan terorisme. Yang mana seringkali muncul akibat memahami Islam dan ilmu pengetahuan secara parsial dan menggunakan metode yang tidak implementatif; juga mengabaikan hal-hal seperti otoritas ulama hingga memahami agama secara destruktif dan kontra-produktif. Hal ini merupakan analisa konten dan tematis atas urgensi skema pendidikan Islam dengan skema di atas. Sehingga, secara kritis; dapat disimpulkan bahwa kurangnya pemahaman agama yang komprehensif, berikut kesalahan metode serta langkah dalam menuntut ilmu agama, mendorong memahami agama secara tekstual, rigid, dan mendorong aksi yang radikal dan menjurus pada terorisme (Brown and Saeed, 2015; Rohadi, 2017).

\section{Hasil Penelitian dan Pembahasan}

\section{Peran dan Proses Pendidikan dalam Islam}

Islam sebagai agama yang toleran, tidak terlepas dari keteladanan Rasūlullāh saw. Sebagai kepercayaan (aqīdah) dan peradaban (hadhārah) sekaligus, ajaran Islam dapat tercermin dari Rasūlullāh saw sebagai rahmatan lil-'älamīn dalam berbagai perilakunya yang telah ditiru oleh sahabat hingga para tābiīn, yang semangatnya dapat kita rasakan hingga saat ini. Pada masa penyebarannya, Islam telah 'membumi' dengan berbagai caranya. Namun sejatinya, faktor terbesar yang mempercepat 'pembumian' Islam adalah kemajuan budaya ilmu dalam Islam itu sendiri. (Zarkasyi, 2015b) Hal ini sejalan dengan visi Islam tentang pengetahuan; bahwa 'ālam diciptakan Allah sebagai 'tanda' akan kekuasaan-Nya. Yang mana, 'tanda-tanda' tersebut perlu direnungkan dengan kalbu (qalb) dan akal ('aql); serta sarana dan prasarana pencapaiannya berupa panca indera dan sumber epistemologi lainnya. (Ahmed, 2018)

Dasar filosofis itulah yang mendorong pencapaian etos dakwah dan etos ilmiah sebagai motivasi tersebarnya Islam: yakni dakwah dan mencari ilmu, serta menegakkan keadilan sosial bagi masyarakat yang dilindunginya. Yang mana, dalam praktiknya menekankan al-amr bi alma'rūf wa al-nahy 'an al-munkar. (Woods, 2006) Sesuatu yang ma'rūf tentu berupa nilai-nilai kebajikan (al-khair), kebenaran (al-haqq), kebijaksanaan (hikmah), kedamaian (salām), perbaikan (ișlāh), pemakmuran (ta'mīr), tolong menolong (ta'ārun) dan lainnya. Sedangkan mencegah dari yang munkar, yakni larangan Islam tentang perbuatan yang merusak ( fasād), keji (fāhisy), kekerasan (ghildzah), aniaya (dzulm), melampaui batas (ghuluw atau $\left.i^{\prime} t i d \bar{a}^{\prime}\right)$, dusta (kidzb), dengki (hasad), dan lainnya. Sikap dan kapasitas seorang muslim yang berdimensi sedemikian, dapat terpancar apabila individunya melalui proses pendidikan yang baik dan tepat (Rippin and Cook, 2004; 
'Commanding Right and Forbidding Wrong As a Principle of Social Action', 2014).

Pendidikan, sebagai suatu proses penanaman (instilling) sifat-sifat yang baik ke dalam diri peserta didik; merupakan sebuah usaha memperkenalkan cara-cara bersikap yang tepat ('adl), serta bijaksana (hikmah) dalam menghadapi segala hal dalam kehidupan. (Ardiansyah et al., 2017; Yazid, 2018) Sikap yang tepat perlu didasari akan pengenalannya terhadap nilai-nilai yang benar dan luhur; baik bersumber dari ajaran agama (syarīah) atau kearifan lokal ('urf), hingga perkembangan ilmu pengetahuan kontemporer lainnya. (Luthfi, 2016; M., 2017) Hal ini mengandaikan penguasaan mendasar terhadap ilmu-ilmu ālat dalam Islam seperti bahasa, al-Qur'an, Hadits, hingga Fiqh dan Ushul Fiqh; (Zarkasyi, 2015a; Dahlan, 2018) juga ilmu-ilmu kontemporer yang sedang berkembang dan teknologi-informasi. Pembelajaran ini pun perlu kematangan orientasi; (Shah, 2001; Al-Attas, 2003; Bakar, 2016) bahwa secara fungsional, tujuan pendidikan adalah menciptakan orang yang baik lagi sempurna akhlaknya karena didasari dengan ilmu. Hal ini dapat kita temukan dalam literatur sebagai 'insān kāmil dalam pemikiran ulama muslim serta filsufnya.

Urgensi tersebut, sangat sesuai dengan visi kenabian Rasulullah Muhammad saw. Yakni, 'menyempurnakan akhlak yang mulia' juga sebagai rahmat bagi semesta alam. Karena itulah, berbagai ulama menekankan sikap yang benar dalam menjadi seorang țâlibul ilmi. Hal ini dapat kita temukan relevansinya dalam berbagai literatur ulama yang jama' dipelajari di pesantren, semisal Ihyā' Ulūmiddīn atau Ta'ไ̄̄m Muta'allim juga kitab-kitab lainnya. Dalam berbagai kitab tersebut, kita akan selalu menemukan nasehat ulama atau penulis di dalamnya mengenai 'sikap yang tepat' dalam menuntut ilmu. Sebagaimana pula diafirmasi oleh Prof. Dr. H. A. Mukti Ali; yang menulis karya 'Ta'limu al-Muta'allim versi Imam Zarkasyi”, yang secara khusus membahas perbandingan metodologi pendidikan agama di abad pertengahan dan di Pondok Modern Darussalam Gontor Ponorogo. (Abdul, 1991)

Skema pendidikan Islam tergolong sebagai long-life education. Slogannya saja 'uthlub al-ilma min al-mahdi ila al-lahdi', 'lan tanāla al-ilma illa bi-sittatin... wa țūlu zamānin'. (Ulum, 2018) Slogan tersebut, merepresentasikan pesantren dan tradisinya di masa lampau. Di mana para kiai yang merupakan ulama di satu pesantren, merupakan spesialis dalam bidang ilmu tertentu. Sehingga di masa lalu, saat seorang santri akan menuntut ilmu hadit misalnya, ia berguru pada guru tertentu. Kemudian, saat ingin menuntut ilmu hadits, ia perlu berguru pada guru lainnya. Hal ini merupakan gambaran akan pentingnya pengakuan otoritas keilmuan antar ulama, yakni memiliki ilmu yang bersanad. Melalui proses yang 
demikian, seorang santri mempelajar adab dan ilmunya sekaligus; melalui sumber yang otoritatif pula. (Avivy and Dakir, 2012; Bizawie, 2015; Suhendra, 2019) Bahkan tidak mengherankan bahwa zaman dahulu, para santri belajar tanpa mengenal perbedaan umur. Di suatu pesantren bahkan terdiri atas berbagai umur; hingga terdapat santri dengan umur yang cukup senior dan sudah menikah. Bahkan, kemampuan intelektual para santri tersebut beragam. Ada pula yang sudah pernah mondok di tempat lain, dan ada pula yang baru pertama mondok. Ada pula yang mondok dalam waktu yang lama; yang bahkan berujung dijadikan santri senior atau menantu sang kiai.

Tentu saja, skema țalabul ilmi tersebut, tentu akan memakan waktu yang cukup dalam prosesnya. Karena itulah, para praktisi pendidikan di masa kemudian memetakan spesifikasi yang standar bagi output suatu lembaga pendidikan yang dibuatnya. Pemikiran ini merupakan adaptasi atas pembaharuan pemikiran pendidikan di tanah air pada masa itu. Demikian pula hadirnya berbagai metode pembelajaran, seperti metode langsung (direct method) dalam pengajaran bahasa, juga kegiatan ekstrakurikuler berupa olahraga dan seni. Bahkan juga, keberhasilan integrasi antara ilmu agama dan ilmu umum makin terlihat penting; dan sudah beberapa lembaga pendidikan yang berhasil melakukan hal tersebut, khususnya pesantren modern. (Dhofier, 1994; Kurniawan, 2018) Bahkan ada pula lembaga pendidikan yang memiliki visi hingga pendirian pendidikan tinggi sebagai lanjutan dari lingkungan sekolah menengahnya. Hal ini pun, nampaknya mendorong perubahan fundamental pada struktur kurikulum, metode mengajar, hingga sarana-prasarana, serta orientasi dan lainnya. Bahkan juga, visi dan misi lembaga pendidikan modern perlu dirumuskan secara terstruktur serta dijalankan secara konsisten untuk urgensi tersebut. (Daud, 1998; Zarkasyi, 2015a; Ahmed, 2018; Ma'Arif, 2018; Ainissyifa, 2019)

Sejatinya, problem dan pemikiran mengenai urgensi dan proses pendidikan telah mendorong para ulama, bahkan juga ilmuwan dalam berbagai peradaban sebelum al-Qur'an diturunkan, untuk melakukan klasifikasi pengetahuan. (Sa'ari, 1999; Musadad, 2015; Ishaq and Daud, 2017) Dalam Islam, upaya ini didasari akan kesadaran bahwa manusia mampu memperoleh ilmu melalui berbagai saluran; yang secara garis besar terbagi dua: 1) Pemberian dari Tuhan (revealed) dan 2) Didapat melalui usaha manusia (acquired). Dalam perkembangannya, ada yang membagi sebagai 1) Ilmu agama (religious sciences) dan 2) Ilmu Umum, baik ilmu alam maupun ilmu sosial (natural and social sciences) (Samawi Hamid, 2003; Kholili, 2014) dan masih banyak lainnya. Berbagai perbedaan dalam disiplin ilmu pun, turut mendorong keragaman metodologi dan program riset-nya. Dengan klasifikasi tersebut, sejatinya dapat dipetakan 
kebutuhan-kebutuhan dan tantangan umat dalam konteks kekinian yang senantiasa berkembang.

\section{Fardhu 'Ain dan Fardhu Kifāyah}

Jika melihat pendidikan dari sisi manfaat, khususnya peran dan fungsinya; juga urgensi dan tantangannya, perlulah diketahui secara mendasar orientasi dan tujuan atau kepentingannya. Berdasarkan kepentingannya, Imām al-Ghazālī membagi 'kepentingan' hidup manusia untuk dua hal; yakni untuk dunia dan akhirat. Sehingga, klasifikasi ilmu dalam pandangan Ghazali memiliki ciri khas yang khusus. Apalagi jika merujuk ke beberapa karyanya: 1) - a) Ilmu yang 'tiba' dengan sendirinya

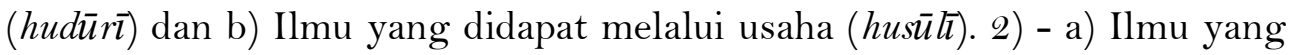
diwahyukan (syariah) dan b) Ilmu rasional (aqliyyah). 3) - a) Ilmu teoritis (nazariyah) dan b) Ilmu praktis ('amaliyah). Kesemua pembagian tersebut dapat kita temukan dalam al-Risālah al-Läduniyyah. Selain itu, ada pula pembagian ilmu dengan kategori Fardhu 'Ain dan Fardhu Kifâyah; yang dapat kita temukan dalam Ihyā' Ulümiddīn. (Sa’ari, 1999; Gilani and Islam, 2018)

Hal ini tidak jauh dari ungkapan al-Zarnūjī, yang menekankan; bahwa pencarian ilmu, haruslah dengan tujuan yang tepat beserta metodenya. Selain itu, tidak diwajibkan bagi seorang muslim untuk mencari segala ilmu dan menguasainya; melainkan memperhatikan aspek yang berkaitan dengannya: yang wajib maupun tidak. Misalnya, bagi seorang muslim, shalat adalah wajib. Maka mengetahui tata cara mengerjakan shalat beserta rukunnya adalah wajib. Lain lagi, seorang pedagang muslim; jika ingin berhasil dalam berdagang, ia perlu mengetahui mana transaksi atau barang yang halal atau haram. Sehingga ia dapat terhindar dari yang haram dan mampu memilih yang halal. (Zarnūjīi, 2003, p. 5)

Skema keilmuan yang sedemikian rupa, sejatinya telah diterapkan di pesantren. Yakni, terciptanya pembelajaran kurikuler secara integratif; yakni antara agama dan ilmu umum, baik ilmu sosial maupun ilmu alam. Hal ini mengikuti metodologi pembelajaran ulama terdahulu, yang tidak memisahkan antara kesalehan pribadi dengan kesalehan sosial; serta mengedepankan keteladaan diri dalam melaksanakan proses pendidikan dan pengajaran. (Azra, 2015; Zarkasyi, 2015a; Siswanto, 2017) Keteladanan tersebut muncul dalam bentuk kemandirian kiai dan keluarga pendiri, serta kezuhudan mereka dalam kehidupan sehari-hari. Bahkan, di pesantren salaf para kiai-kiai kebanyakan tidak mengambil iuran dari santrinya; dan para santri seolah menjadi bagian dari keluarga sang kiai. Para santri seringkali membantu kiai secara sukarela dalam keberlangsungan sistem pondok. Karena secara historis, pondok berdiri dimulai dari adanya santri yang 
menuntut ilmu kepada seorang alim. Kelanjutannya, dengan semakin banyaknya santri; inisiatif pendirian pondok-pondok untuk tempat tinggal pun muncul. Dan demikian berlanjut hingga masa perkembangan dan pasang surutnya. (Gazali and Malik, 2009; Falah, 2019)

Dari segi kurikulum; dengan latar belakang tersebut, telah berhasil dalam mengintegrasikan pengajaran agama yang menjadi fardhu 'ain bagi santri, serta ilmu-ilmu alat lainnya hingga ilmu sosial dan ilmu alam sebagai bagian yang fardhu kifâyah. Ditambah lagi, kurikulum pendidikan agama sebagai fardhu 'ain memiliki jenjang yang beragam. Di awal masa studi, biasanya santri diajarkan untuk dapat melaksanakan ibadah yang ada dalam rukun Islam; berikut pula praktik manasik haji. (Muazza et al., 2018) Bahkan terdapat pula jenjang membaca kitab kuning (turāts) hingga literatur 'setingkat' mujtahid seperti Bidāyatul Mujtahid dan Bulūghul Marām. Hal ini menunjukkan perhatian pendidikan pesantren atas ilmu fardhu 'ain yang menjadi salah satu orientasi pesantren, yakni Ke-Islaman. Bagian ilmu umum, yakni ilmu sosial dan ilmu alam turut mendapat tempat. Santri diajarkan berhitung, matematika, fisika, geografi, hingga psikologi, sosiologi, hingga ilmu alat berupa bahasa Arab dan Inggris serta yang cukup rumit seperti mantiq. Pengajaran ilmu umum tersebut, didasari akan kebutuhan masyarakat atasnya. Dari sinilah, orientasi pesantren mulai mengerucut pada keilmuan dan kemasyarakatan. (Munjahid, 2011; Zarkasyi, 2015a)

Di luar kurikulum kelas, terdapat pula media dan wahana untuk mempraktikkan keilmuan fardhu 'ain tersebut; yakni dalam berbagai kegiatan pondok yang berdimensi keagamaan, di antaranya adalah menjadi imam shalat di asrama, hingga di masjid. Bahkan turut mendapat kesempatan untuk khutbah Jumat, atau bahkan memimpin tahlil atau pengajian di masyarakat umum. Melalui media itulah, adab dan akhlak santri diasah; yakni dengan interaksi bersama masyarakat, tokoh, hingga lainnya. Dari latihan inilah timbul adab yang baik, toleran, serta santun. Belum lagi, adanya kegiatan harian di asrama dan kelas. Yang mana, di hari libur; seringkali diadakan pembersihan asrama maupun kelas di bawah koordinasi kakak kelas maupun guru; serta ditinjau langsung oleh kiai. (Fua et al., 2018)

Dengan latar belakang yang sedemikian, pesantren memiliki kultur keilmuan yang unik. Yang cenderung identik dengan kharisma dan kepemimpinan kiainya. Metode pembelajarannya pun beragam. Bukan hanya menyoroti aspek 'transfer ilmu' saja, namun ada pula 'transfer adab' bahkan juga 'transfer doa'. Hal ini terlihat dari motivasi santri dalam menuntut ilmu; yakni 'ngalap barokah' atau mengharap restu kiai dan doanya, karena adanya pandangan bahwa doa guru adalah mustajāb. Mengingat posisi kiai sebagai otoritas di pesantren, seringkali suatu pesantren menganut tarekat tertentu. Hal ini diturunkan secara bersanad; 
yakni tarekat yang mu'tabar. (Muhaimin, 1997; Kunci, Interaksi Kyai-Santri and Belajar Santri dan Kewibawaan Kharismatik Kyai, 2008; Bizawie, 2015) Melalui skema proses tersebut, seringkali santri 'mendapat berkah' dalam bentuk bertambahnya ilmu, kemudahan dalam beramal, maupun kemampuan untuk bergaul di masyarakat secara luas; dengan misi rahmatan lil-ālamin. Yakni sembari mengamalkan ilmu dari meneladani akhlak kiai dalam kehidupannya sehari-hari. (Hamid and Juliansyahzen, 2017; Pribadi, 2018).

\section{Relevansi Pendidikan Islam sebagai anti Terorisme}

Sebagaimana pesan mendasarnya; bahwa makna Islam berarti 'damai'; yakni dari kata salām. Sehingga, titik berat dari berislam adalah menjadi pribadi yang damai. Secara khusus, Rasūlullāh saw menegaskan bahwa orang Islam adalah (al muslimu man salima min lisanihi wa yadihi). Nilai-nilai kedamaian yang sedemikian, telah nyata secara esensial dipraktikkan dalam dakwah para walisongo sekalipun; bahkan semakin kuat ketika dilembagakan secara tradisional dalam bentuk pondok pesantren. Sehingga, sudah menjadi barang tentu bahwa alumni pesantren memiliki ciri khas yang toleran, tidak mudah terjebak perpecahan dan perdebatan seputar Madhzab Fiqh. (Maksum, 2016; Putra, 2016)

Spirit pendidikan Islam di Indonesia sendiri, justru dominan diperankan oleh lembaga swasta; khususnya pesantren. Dalam pesantren, Tradisinya keilmuannya yang unik, justru menyediakan kunci bagi murid untuk mengembangkan keilmuannya dalam tingkat yang lebih tinggi. Dengan syarat, tentu saja; tidak mengabaikan dasar-dasar dan aspek filosofis dalam pencarian ilmu tersebut. Dasar-dasar tersebut, telah ditanamkan secara praktis dalam penanaman adab dalam jiwa siswa melalui kegiatan dan interaksi dengan kiai; serta perilaku keteladanan santri senior dan juga kiainya. (Husaini, 2013; Nuriz and Awang, 2017; Rizal, Iqbal and MA, 2018) Penanaman adab tersebut, diasah secara nyata melalui penugasan yang diberikan oleh kiai kepada santri untuk turut mengelola dinamika kehidupan di pesantren. Semakin tinggi tingkat kesulitan tugasnya, tentu semakin tinggi pula kepercayaan sang kiai kepadanya. Dalam pandangan santri sebagai murid, penugasan tersebut merupakan hal yang sakral dan perlu dijalankan secara amanah dan sungguh-sungguh. Meski kadangkala tugas tersebut bertentangan dengan 'akal sehat' atau 'ide-ide rasional' yang jamak beredar; namun tetap juga dilaksanakan dengan penuh khidmah. Motivasinya adalah mendapat restu dan 'ngalap barokah' dari sang kiai tersebut. (Nilan, 2009; Pondok et al., 2012; Masqon, 2014; Solichin, 2018; Ulum, 2018)

Pada fase tersebut, kedekatan (shuhbah) antara kiai dengan santri mempermudahnya mendapatkan ilmu dari kiai tersebut. Bahkan, melalui berbagai penugasan tersebut; santri mendapatkan ilmu teoritis maupun 
praktis sekaligus; juga termotivasi dari keteladanan sang kiai tersebut. Sejalan dengan itu, lingkungan pondok yang sederhana dan seringkali memiliki fasilitas yang terbatas, mendorong untuk mampu hidup sederhana; juga sabar dalam menggapai tujuan dan cita-cita. Bukan hanya itu, di pesantren bercorak modern; kegiatannya telah dijadwal sedemikian rupa. (Vida, von Grunebaum and Abel, 1948; Abdul, 1991; Huda et al., 2016) Ditambah dengan sistem kontrol hirarkis dari kiai kepada guru senior, lalu guru junior, hingga santri senior terhadap junior; serta hal-hal yang mendorong implementasi praktis guna pengamalan ilmu yang telah didapat melalui pelajaran dengan sistem klasikal (pembagian santri ke dalam berbagai kelas). Sehingga, para santri mendapatkan 'pengajaran' (ta'līm) di kelas dari gurunya; serta mendapatkan 'pengasuhan' (tarbiyah) dan 'pendidikan' (ta'dīb) saat ia berkegiatan bersama seniornya, guru, hingga kiainya. Kesemua program tersebut, di bawah kendali kiai sebagai pemimpin otoritas tertinggi di pesantren; sekaligus juga pemimpin spiritual. (Hamid and Juliansyahzen, 2017)

Pembiasaan yang secara sistemik dan masif tersebut, menempa karakter santri sebagai peserta didik. Baik di pesantren tradisional maupun modern. Hal ini, membentuk karakteristik peserta didik yang memiliki orientasi seputar keislaman, keilmuan, dan kemasyarakatan sekaligus. Belum lagi, pengajaran ilmu agama sebagai fardhu 'ain yang berjenjang, membuat santri dapat memahami perkara khiläfiyah serta menempatkan diri dengan baik dalam pergaulan masyarakat. (Ma'Arif, 2018) Hal ini menjadi bukti, bahwa santri yang belajar di pesantren dengan sungguhsungguh; mampu 'membaca' ajaran Islam secara keseluruhan, bukan sepotong-sepotong atau bahkan 'terbumbui' fanatik madzhab atau aliran Islam yang menyimpang dan sesat. Pemahaman keagamaan yang sedemikian, tentunya merupakan bekal yang cukup dalam melawan ide-ide memahami Islam secara reduksionaristik; yang mana, merupakan 'pintu masuk' bagi hal-hal semacam terorisme dan radikalisme atau mempertentangkan Islam dengan ilmu pengetahuan dan sains modern. (Abdullah, 2017; Kirana, 2018)

\section{Kesimpulan}

Dalam pendidikan Islam di Indonesia, khususnya pesantren; terdapat berbagai sarana untuk mencegah terorisme. Tradisi intelektual justru perlu ditekankan; karena sejatinya, tantangan zaman ini adalah 'pursuit of knowledge' atau tantangan ilmu. Kehadiran aliran teroris yang mengatasnamakan agama, sejatinya muncul karena ketiadaan adab dan ilmu (meminjam istilah SMN al-Attas sebagai 'loss of adab'); yang mendorong tersebarnya pengetahuan yang tidak benar tentang agama dan cara beragama yang tepat. Akibatnya, agama dijadikan motif berbuat teror; 
dengan dalih, bahwa 'Islam tersebar dengan pedang'. Walhasil, stigma demi stigma pun dilancarkan kepada yang bukan kelompoknya sebagai 'kafir'. Belum lagi, pemahaman yang mendudukkan agama sebagai semacam budaya; bahkan 'memaksa' agar agama tidak masuk ke dalam ruang publik adalah sangat mereduksi makna agama bahkan mempertentangkannya dengan ilmu pengetahuan dan sains modern.

Karena itulah, penguasaan mendasar tentang ilmu fardhu 'ain; yakni pokok-pokok (ușūl) agama, adalah penting. Mengingat ia adalah dasar untuk berdirinya ilmu-ilmu umum, baik sosial maupun kealaman. Penguasaan ilmu tersebut, masih selalu membutuhkan dukungan dari ilmu alat; yakni bahasa. Belum lagi, bimbingan guru yang baik juga amat dibutuhkan dalam membentuk karakternya; apalagi guru yang benar-benar mengajarkan adab padanya. Hal inilah yang juga akan membangun penguasaan ilmu lainnya yang bersifat fardhu kifäyah; yakni manakala ta' $d \grave{\imath} b$ sang guru atau kiai berbentuk penugasan yang berinteraksi langsung dengan beliau. Karena, secara esensial; pesantren melaksanakan tiga terma utama terkait pendidikan sekaligus: tarbiyah, ta' $\bar{\imath} m$, dan ta'd $\bar{\imath}$. Integrasi dari kesemuanya, meningkatkan kemampuan memahami Islam secara holistik dengan ilmu, adab, serta lahir darinya, perilaku yang hikmatis; yang juga bagian dari aspek nilai toleransi yang mencegah aksi terorisme dan radikalisme.

\section{DAFTAR PUSTAKA}

Abdul, M. A. (1991) Ta'limu al-Muta'allim versi Imam Zarkasyi. Ponorogo: Trimurti Gontor.

Abdullah, M. A. (2014) 'Religion, science and culture: An integrated, interconnected paradigm of science', Al-Jami'ah. doi: 10.1442 1/ajis.2014.521.175-203.

Abdullah, M. A. (2017) 'Islamic studies in higher education in Indonesia: Challenges, impact and prospects for the world community', $\mathrm{Al}$ Jami'ah. doi: 10.14421/ajis.2017.552.391-426.

Abu-Munshar, M. Y. (2010) 'The Compatibility of Islam With Pluralism: Two Historical Precedents', Islam and Civilisational Renewal, 1 (4), pp. 613-628,748. Available at: https://search.proquest.com/docview/1314743103? accountid=17215\%250Ahttps://limo.libis.be/se rvices/KULeuven?url_ver=Z39.88-2004\&rft_val_fmt=info:ofi/ fmt:kev:mtx:journal\&genre=article\&sid=proq:proq\%253asocscijour nals\&atitle $=$ the + compatibility + of + islam $+w i t h+p$.

Ahmed, F. (2018) 'An exploration of Naquib al-Attas' theory of Islamic 
education as ta'dīb as an "indigenous" educational philosophy', Educational Philosophy and Theory. Routledge, 50 (8), pp. 786-794. doi: 10.1080/00131857.2016.1247685.

Ainissyifa, H. (2019) 'Development strategy of islamic education institution', International Journal of Scientific and Technology Research, 8 (4), pp. 141-149.

Al-Attas, S. M. N. (2003) 'Islam and the Challenge of Modernity: Divergence of Worldviews', in Hershock, Peter D., Stepaniants, Marietta, T. Ames, R. (ed.) Technology and Cultural Values: On the Edge of the Third Millennium. I. Honolulu.

Alkouatli, C. (2018) 'Pedagogies in becoming muslim: Contemporary insights from islamic traditions on teaching, learning, and developing', Religions. doi: 10.3390/rel9110367.

Ardiansyah, M. et al. (2017) 'The Concept of Adâb by Syed Muhammad Naquib al-Attas and Its Relevance to Education in Indonesia', International Journal of Islamic Education Ta'dibuna, 1 (1), pp. 53-64.

Avivy, A. L. F. and Dakir, J. (2012) 'methodology of writing hadith in the works of Muhammad Nawawi al-Bantani', Journal of Applied Sciences Research.

Azra, A. (2015) 'Genealogy of Indonesian Islamic Education: Roles in the Modernization of Muslim Society', Heritage of Nusantara; International Journal of religious Literature and Heritage.

Bakar, O. (2016) 'Science and Technology for Mankind's Benefit: Islamic Theories and Practices - Past, Present, and Future', in Islamic Perspectives on Science and Technology. doi: 10.1007/978-981-287778-9_3.

Bizawie, Z. M. (2015) 'Sanad and Ulama Network of The Quranic Studies in Nusantara', Heritage of Nusantara, 4 (1), pp. 23-44.

Brown, K. E. and Saeed, T. (2015) 'Radicalization and counterradicalization at British universities: Muslim encounters and alternatives', Ethnic and Racial Studies. doi: 10.1080/01419870.2014.911343.

Chatfield, A. T., Reddick, C. G. and Brajawidagda, U. (2015) 'Tweeting propaganda, radicalization and recruitment: Islamic state supporters multi-sided twitter networks', in ACM International Conference Proceeding Series. doi: 10.1145/2757401.2757408.

'Commanding Right and Forbidding Wrong As a Principle of Social Action (2014) in Global Salafism. doi: 10.1093/acprof:oso/9780199333431.003.0009.

Dahlan, Z. (2018) 'Khazanah Kitab Kuning: Membangun Sebuah Apresiasi Kritis', ANSIRU PAI : Pengembangan Profesi Guru Pendidikan Agama Islam. doi: 10.30821/ansiru.v2i1.1624.

Daud, W. M. N. W. (1998) The Educational Philosophy and Practice of Syed 
Muhammad Naquib al-Attas: An Exposition of the Original Concept of Islamization. Kuala Lumpur: ISTAC.

Dhofier, Z. (1994) 'The role of pesantren in the development of primary education in Indonesia', Studia Islamika. doi: 10.15408/sdi.v 1 i2.857.

Fahmy Zarkasyi, H. (2015) 'Tamaddun sebagai konsep peradaban Islam', Tsaqafah, 11 (1), pp. 1-28.

Falah, S. (2019) 'Model regenerasi dan kaderisasi kepemimpinan pondok pesantren di Kabupaten Bogor', Ta'dibuna: Jurnal Pendidikan Islam. doi: 10.32832/tadibuna.v8i1.1782.

Fua, J. La et al. (2018) 'Islamic Education on Formation of Environmental Awareness in Pondok Pesantren Indonesia', in IOP Conference Series: Earth and Environmental Science. doi: 10.1088/17551315/156/1/012035.

Gazali, H. and Malik, A. (2009) 'Pesantren and the Freedom of Thinking: Study of Ma'had Aly Pesantren Sukorejo Situbondo, East Java, Indonesia', Al-Jami'ah: Journal of Islamic Studies. doi: 10.1442 1/ajis.2009.472.295-316.

Gilani, S. M. Y. and Islam, T. (2018) 'Approaches to Integration of Knowledge: A Study of Al-Ghazali And Alwani's Views (Pendekatan ke Arah Mengintegrasikan Ilmu Pengetahuan: Satu Kajian terhadap Pandangan Al-Ghazali dan Alwani )', Journal of Islam in Asia <span style="font-size: O.6em"> (E-ISSN: 22898077)</span>. doi: 10.31436/jia.v15i2.756.

Hamid, N. and Juliansyahzen, M. I. (2017) 'Prophetic Leadership in Pesantren Education: Study at Pondok Pesantren Universitas Islam Indonesia', Jurnal Pendidikan Islam. doi: 10.14421/jpi.2017.62.349369.

Huda, M. et al. (2016) 'Al-Zarnūjī's Concept of Knowledge ('Ilm)', SAGE Open. doi: 10.1177/2158244016666885.

Husaini, A. (2013) 'Pendidikan Karakter Berbasis Ta'dîb', TSAQAFAH, 9 (2), p. 371. doi: $10.21111 /$ tsaqafah.v9i2.58.

Hussin, N. H., Noh, M. A. C. and Tamuri, A. H. (2014) 'The religious practices teaching pedagogy of Islamic education excellent teachers', Mediterranean Journal of Social Sciences. doi: 10.5901/mjss.2014.v5n16p239.

Ishaq, U. M. and Daud, W. M. N. W. (2017) 'Ibn Al-Haytham'S classification of knowledge', Al-Jami'ah, 55 (1), pp. 189-210. doi: 10.14421/ajis.2017.551.189-210.

Kholili, H. (2014) 'Filsafat Ilmu dan Problem Metodologi Pendidikan Islam', Jurnal At-Ta'dib, 9 (2), pp. 143-159.

Kirana, D. (2018) 'Enhancing religious education: An attempt to counter violent extremism in Indonesia', Studia Islamika. doi: 10.15408 /sdi.v25i1.7284. 
Kunci, K., Interaksi Kyai-Santri, P. and Belajar Santri dan Kewibawaan Kharismatik Kyai, H. (2008) 'Pola Interaksi Kyai-Santri Pengaruhnya Terhadap Hasil Belajar Santri; Studi Determinasi Kewibawaan Kharismatik Kyai', Universitas Negeri Semarang.

Kurniawan, S. (2018) 'Sukarno's thought on the importance of reintegration of religion and science in pesantren education in Indonesia', Journal of Indonesian Islam. doi: 10.15642/JIIS.2018.12.2.219-246.

$\mathrm{Lu}, \mathrm{J}$. and $\mathrm{Yu}, \mathrm{X}$. (2018) 'Does The internet make us more intolerant? A contextual analysis in 33 countries', Information Communication and Society. doi: 10.1080/1369118X.2018.1499794.

Luthfi, K. M. (2016) 'Islam Nusantara: Relasi Islam dan Budaya Lokal', SHAHIH: Journal of Islamicate Multidisciplinary. doi: 10.22515/shahih.v1i1.53.

M., S. (2017) 'Sejarah Pergulatan Politik Hukum Islam Di Indonesia', AlManahij: Jurnal Kajian Hukum Islam. doi: 10.24090/mnh.v 10i2.939.

Ma'Arif, S. (2018) 'Education as a foundation of humanity: Learning from the pedagogy of pesantren in Indonesia', Journal of Social Studies Education Research. doi: 10.17499/jsser.58854.

Maksum, A. (2016) 'Model Pendidikan Toleransi Di Pesantren Modern Dan Salaf, Jurnal Pendidikan Agama Islam (Journal of Islamic Education Studies). doi: 10.15642/pai.2015.3.1.81-108.

Masqon, D. (2014) 'Dynamic Of Pondok Pesantren As Indegenous Islamic Education Centre In Indonesia', EDUKASI: Jurnal Penelitian Pendidikan Agama dan Keagamaan. doi: 10.32729/edukasi.v 12i1.78.

Matua, G. A. and Van Der Wal, D. M. (2015) 'Differentiating between descriptive and interpretive phenomenological research approaches', Nurse Researcher, 22 (6), pp. 22-27. doi: 10.7748/nr.22.6.22.e1344.

Moser, A. and Korstjens, I. (2018) 'Series: Practical guidance to qualitative research. Part 3: Sampling, data collection and analysis', European Journal of General Practice. doi: 10.1080/13814788.2017.1375091.

Muazza, M. et al. (2018) 'Education in Indonesian islamic boarding schools: Voices on curriculum and radicalism, teacher, and facilities', Islamic Quarterly.

Muhaimin, A. G. (1997) 'Pesantren and Tarekat in the Modern Era: An account on the transmission of traditional Islam in Java', Studia Islamika, 4 (1), pp. 1-28. doi: 10.15408/sdi.v4i1.785.

Munjahid (2011) 'Sekularisasi Pesantren (Studi Analisis atas Dinamika Kurikulum Pesantren)', Cendekia: Jurnal Kependidikan Dan Kemasyarakatan. doi: 10.21154/CENDEKIA.V9I 1.859.

Musadad, A. N. (2015) 'Klasifikasi Ilmu Pengetahuan Dalam Perspektif Jābir Bin Hayyān', Kanz Philosophia: A Journal for Islamic Philosophy 
and Mysticism, 5 (2), p. 115. doi: 10.20871/kpjipm.v5i2.126.

Nilan, P. (2009) 'The "spirit of education" in Indonesian Pesantren', British Journal of Sociology of Education. doi: 10.1080/01425690802700321.

Nuriz, M. A. F. and Awang, J. (2017) 'Character Education: Study of Burhanuddin Al-Zarnuji and Imam Zarkasyi's Thought', Jurnal Sultan Alauddin Sulaiman Shah, 4 (1), pp. 46-59.

Pondok, D. et al. (2012) 'Kepemimpinan Kiai dalam Memelihara Budaya Organisasi', Kepemimpinan Kiai dalam Memelihara Budaya Organisasi.

Pribadi, Y. (2018) 'Pesantren Pluralis: Peran Pesantren Ngalah dalam Mengembangkan Nilai-nilai Pluralisme di Tengah Masyarakat yang Multikultural, by M. Muntahibun Nafis', Bijdragen tot de taal-, land-en volkenkunde / Journal of the Humanities and Social Sciences of Southeast Asia. doi: 10.1163/22134379-17402014.

Putra, B. A. (2016) 'Islam dalam Sejarah dan Kebudayaan Melayu', Humankia, 1 (2), pp. 193-216.

Rippin, A. and Cook, M. (2004) 'Commanding Right and Forbidding Wrong in Islamic Thought', Journal of the American Oriental Society. doi: $10.2307 / 4132164$.

Rizal, M., Iqbal, M. and MA, N. (2018) 'Model Pendidikan Akhlaq Santri di Pesantren dalam Meningkatkan Akhlaq Siswa Di Kabupaten Bireuen', Nadwa. doi: 10.21580/nw.2018.12.1.2232.

Rohadi, T. (2017) 'Deradicalization Through Multicultural and Local Wisdom Literacies Based Teaching Model at Salaf and Kholaf Pesantren in West Java', Ijtimā'iyya: Journal of Muslim Society Research. doi: http://dx.doi.org/10.24090/jmsr.v2i1.2017.pp2 1-42.

Sa'ari, C. Z. (1999) 'Classification of Sciences: A Comparative Study of Iḥyā' 'ulūm aI-dīn and al-Risālah al-laduniyyah', Intellectual Discourse, 7 (1), pp. 53-77.

Samawi Hamid, I. (2003) 'Classification of Knowledge in Islam: A Study in Islamic Philosophies of Science, by Osman Bakar. (Islamic Texts Society, 1998), 330 pages, index. \$29.50 (Cloth) ISBN 0-94662171-3, Middle East Studies Association Bulletin, 36 (2), pp. 206-207. doi: $10.1017 / \mathrm{s} 0026318400044886$.

Shah, M. H. (2001) 'Contemporary Muslim Intellectuals and Their Responses to Modern Science and Technology', in Ahmad, M. and Mir, M. (eds) Studies in Contemporary Islam. Youngstown State University: Centre for Islamic Studies.

Shaw, I. S. (2012) 'Stereotypical representations of Muslims and Islam following the $7 / 7$ London terror attacks', International Communication Gazette. doi: 10.1177/1748048512454816.

Siswanto, S. (2015) 'Perspektif Amin Abdullah tentang IntegrasiInterkoneksi dalam Kajian Islam', Teosofi: Jurnal Tasawuf dan 
Pemikiran Islam. doi: 10.15642/teosofi.2013.3.2.376-409.

Siswanto, S. (2017) 'Madrasah Unggulan Berbasis Pesantren', Ulumuna. doi: 10.20414/ujis.v18i1.157.

Solichin, M. M. (2018) 'Interrelation Kiai Authorities, Curriculum and Learning Culture in Pesantren Indonesia', TARBIYA: Journal of Education in Muslim Society. doi: 10.15408/tjems.v5i1.7781.

Suhendra, A. (2019) 'Transmisi Keilmuan Pada Era Milenial Melalui Tradisi Sanadan Di Pondok Pesantren Al-Hasaniyah', Jurnal SMART (Studi Masyarakat, Religi, dan Tradisi). doi: 10.18784/smart.v5i2.859.

Ulum, M. M. (2018) 'Penerapan Konsep Țūlu Az-Zamān Menurut AzZarnuji Di Pondok Pesantren Asma' Chusna Kranji Kedungwuni Pekalongan', Jurnal PROGRESS: Wahana Kreativitas dan Intelektualitas. doi: 10.31942/pgrs.v6i2.2539.

Vida, G. L. Della, von Grunebaum, G. E. and Abel, T. M. (1948) 'AzZarnūjīi , Ta'līm al-Muta'allim-Tarīq at-Ta'-allum. Instruction of the Student: The Method of LearningAz-Zarnuji, Ta'lim al-Muta'allimTariq at-Ta'-allum. Instruction of the Student: The Method of Learning', Journal of the American Oriental Society. doi: $10.2307 / 595783$.

Woods, T. J. (2006) 'Islam, Peace and the Quest for Justice', Theology. doi: $10.1177 / 0040571$ X0610900603.

Yazid, A. (2018) 'JRTIE: Journal of Research and Thought of Islamic Education Vol. 1, No. 1, 2018', Journal of Research and Thought of Islamic Education, 1 (1), pp. 1-21.

Zarkasyi, H. F. (2012) 'Liberalism, Liberalization and Their Impacts of Muslim Education (Special Case of Indonesian Intellectuals)', TSAQAFAH, 8 (1), p. 183. doi: 10.21111/tsaqafah.v8i1.23.

Zarkasyi, H. F. (2015a) 'Modern Pondok Pesantren: Maintaining Tradition in Modern System', TSAQAFAH, 11 (2), p. 223. doi: 10.21111/tsaqafah.v11i2.267.

Zarkasyi, H. F. (2015b) 'Tamaddun sebagai Konsep Peradaban Islam', TSAQAFAH, 11 (1), p. 1. doi: 10.21111 /tsaqafah.v11i1.251.

Zarnūjī, B. al-D. (2003) Instruction of the Student: The Method of Learning. Edited by G. E. Grunebaum and T. M. Abel. New York: Starlacth Press. 